Original article

\title{
A newly developed age estimation method based on CpG methylation of teeth-derived DNA using real-time methylation-specific PCR
}

\author{
Masahiro Kondo' ${ }^{1)}$, Hirofumi Aboshi ${ }^{1)}$, Masaaki Yoshikawa ${ }^{2}$, Ayano Ogata ${ }^{1)}$, Ryosuke Murayama ${ }^{1)}$, Masami Takei ${ }^{3)}$, \\ and Shin Aizawa ${ }^{2}$
}

${ }^{1)}$ Department of Legal Medicine, Nihon University School of Dentistry, Tokyo, Japan

${ }^{2)}$ Division of Anatomical Science, Department of Functional Morphology, Nihon University School of Medicine, Tokyo, Japan

${ }^{3}$ Division of Hematology and Rheumatology, Department of Medicine, Nihon University School of Medicine, Tokyo, Japan

(Received March 23, 2020; Accepted July 2, 2020)

\begin{abstract}
Age estimation of unidentified bodies is important in forensic medicine and crime scenes. There is accumulating evidence that DNA methylation in the human genome isolated from body fluids changes with age. Most of the data have been obtained by pyrosequencing. In the forensic field, a simple, quick, and economical method is required to evaluate the age of various types of samples. In this study, an age estimation method based on methylation levels of DNA extracted from teeth using real-time methylation-specific PCR (MSP) was developed. The $\mathrm{CpG}$ island in the upstream region of ELOVL2, which is known as a validated biomarker in blood samples, was selected as a target site. The $\mathrm{CpG}$ methylation levels highly correlated with age $(\mathrm{r}=0.843, n=29)$. Age-related increase in DNA methylation levels was not affected by sex differences. In addition, the simple regression model based on methylation status of the $\mathrm{CpG}$ island exhibited moderate accuracy with a mean absolute deviation between chronological age and predicted age of 8.94 years. The results imply that real-time MSP can be a new tool to perform age prediction of unidentified bodies in forensic scenes.
\end{abstract}

Keywords; age estimation, bisulfite conversion, $\mathrm{CpG}$ islands, DNA methylation, ELOVL2, forensic age

\section{Introduction}

Age determination of body remains can be crucial to forensic scientists to narrow down identified or unidentified individuals. To date, a large number of methods have been proposed to evaluate the age of death $[1,2]$.

The standard method of age estimation in forensic scenes is mainly through the morphology of skeletal remains and teeth collected from the deceased [1], however it requires a wealth of experience to predict the age with accuracy. On the other hand, molecular-based analysis, such as quantification of aspartic acid racemization in dentin, radiocarbon dating of tooth enamel, measurement of shortening telomere length and of mitochondrial DNA mutation, have also been proposed [3,4]. Although these quantitative methods allow more objective decisions on age estimation, accuracy is not always high.

The DNA methylation of cytosine residues has been considered as an epigenetic change involved in the regulation of gene expression $[5,6]$. When observing the whole genome, it can be seen that $60-90 \%$ of $\mathrm{CpGs}$ are methylated in human beings [5]. In contrast, the cytosine residues in the $\mathrm{CpG}$ island existing in the promoter region of genes are initially hypomethylated. The $\mathrm{CpG}$ methylation level gradually increases, or decreases in some cases, during development and cellular differentiation. The status of methylation is preserved during DNA replication and is inherited after cell division [6].

Recently, there is accumulating evidence that DNA methylation can be used to verify age estimation $[7,8]$. In initial studies, genome-wide DNA

Correspondence to Dr. Masahiro Kondo, Department of Legal Medicine, Nihon University School of Dentistry, 1-8-13 Kanda-Surugadai, Chiyoda-ku, Tokyo 101-8310, Japan

Fax: 81-3-3219-8343 E-mail: kondou.masahiro@nihon-u.ac.jp

J-STAGE Advance Publication: December 7, 2020

Color figures can be viewed in the online issue at J-STAGE.

doi.org/10.2334/josnusd.20-0138

DN/JST.JSTAGE/josnusd/20-0138 methylation profiling, such as Illumina (San Diego, CA, USA) Infinium HumanMethylation450K BeadChip array, was used to identify a large number of $\mathrm{CpG}$ sites that are significantly correlated with age [8]. For example, Hannum et al. established a quantitative model of senescence based on the $71 \mathrm{CpG}$ sites selected from the Illumina BeadArray technology (mean absolute deviance $[\mathrm{MAD}]=4.9$ years) [9]. In the same way, Garagnani et al. discovered that methylation status of 3 regions, the $\mathrm{CpG}$ islands of 3 genes including ELOVL2, strongly correlates with age on whole blood-derived DNA [10]. The degree of age-dependent DNA methylation varies depending on the genes, tissues and cell types [11].

On the other hand, Weidner et al. built an aging clock derived from human blood that could predict age using $3 \mathrm{CpG}$ sites located on the ITGA2B, ASPA, and PDE4C gene using bisulfite pyrosequencing [12]. Subsequently, studies with different samples by several groups confirmed that the ELOVL2 can be an excellent biomarker for age estimation at forensic scenes [13-15]. Most of these experiments were performed using bisulfite pyrosequencing. Indeed, the sequencing-based analysis is an excellent method in that it can obtain information on which GC sites on the genome methylation has occurred. It is, however, time-consuming and costly to analyze.

Methylation-specific PCR (MSP), which was initially reported by Herman et al., can quickly assess the methylation status of virtually any group of $\mathrm{CpG}$ sites within a $\mathrm{CpG}$ island without a sequencing step, and needs only a small amount of DNA [16]. It should be also emphasized that the method can be performed without specific equipment.

As forensic identification of human remains that are severely damaged or degraded, bone and teeth are frequently the only available sources of DNA. Furthermore, teeth are especially important as a sample for victim identification in large-scale disasters. Nevertheless, age estimation models based on DNA methylation level have been developed using body fluid, particularly blood. In this study, a tooth-derived DNA-based age estimation model based on a semi-quantitative analysis of DNA methylation by real-time MSP was developed.

\section{Materials and Methods}

This study was approved by the Ethics Committee of Nihon University School of Dentistry (approval \#EP19D007). All experiments in this study were performed following the Japanese ethical guidelines for human genome/gene analysis research, Ministry of Health, Labor and Welfare of Japan.

\section{DNA extraction}

Twenty-nine teeth (from 20 to 79 years old) that had been stored in the laboratory were used in this study. Each sample had been carefully conserved in a paper bag, a plastic bag, or a small glass bottle. The teeth were soaked in $5 \%$ sodium hypochlorite solution for a few minutes and then washed with a toothbrush under running distilled water to remove debris.

Genomic DNA was extracted from the teeth using a TBONE EX KIT (DNA Chip Research Inc., Tokyo, Japan) followed by phenol extraction. Briefly, the teeth samples were soaked in $30 \mathrm{~mL}$ solution $\mathrm{A}$ at $23^{\circ} \mathrm{C}$ for overnight. Following this, $1.8 \mathrm{~mL}$ of solution $\mathrm{B}$ was added to the same tube. The mixture was incubated at $37^{\circ} \mathrm{C}$ for $2 \mathrm{~h}$ to decalcify the samples. After discarding the supernatant, $400 \mu \mathrm{L}$ of solution $\mathrm{C}$ and $50 \mu \mathrm{L}$ of Proteinase 
Table 1 Primer sequences used for the methylation specific PCR.

\begin{tabular}{lll}
\hline Target & Primer Names & Sequence $\left(5^{\prime}-3^{\prime}\right)$ \\
\hline ELOVL2 & ELOVL2-F & TTTACGGAGTTTTAGGAATATTTATTC \\
& ELOVL2-R & CCAACTATAAACAAAACCAACGTA \\
Alu & ALU-F & GGTTAGGTATAGTGGTTTATATTTGTAATTTTAGTA \\
& ALU-R & ATTAACTAAACTAATCTTAAACTCCTAACCTCA \\
\hline
\end{tabular}

A

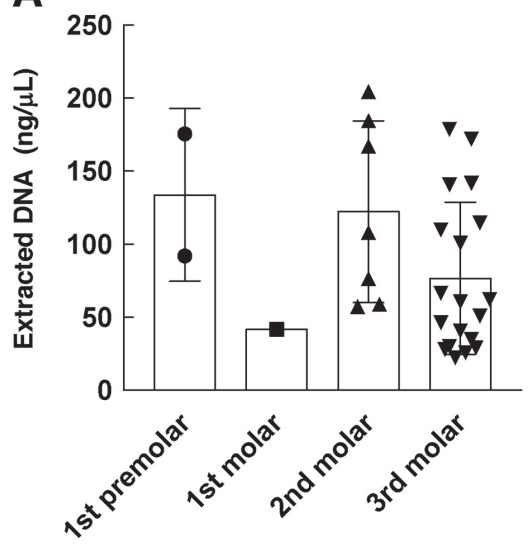

Type of tooth
B

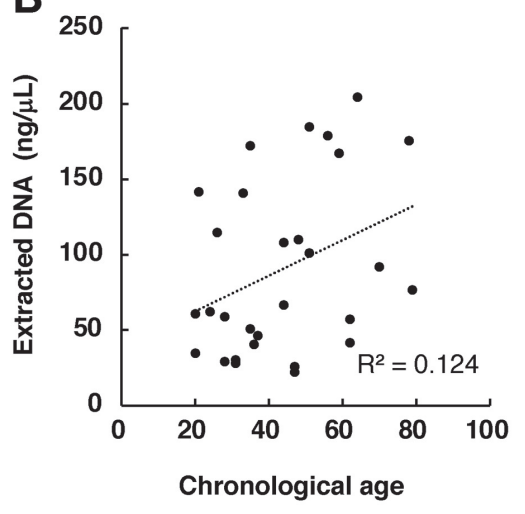

Fig. 1 Genomic DNA extraction from teeth. (A) Bar graph showing the relationship between the amount of extracted DNA and the type of tooth. There is no difference in DNA content depending on the type of tooth. (B) Dispersion diagrams of extracted DNA from 29 teeth samples against chronological age of the donor. The DNA contents of teeth are not affected by the age of individuals who provide the teeth $(r=0.353)$.

$\mathrm{K}(20 \mathrm{mg} / \mathrm{mL})$ were added to the samples. The mixture was incubated at $56^{\circ} \mathrm{C}$ for $3 \mathrm{~h}$ for digestion. The supernatant was collected in a new tube containing $400 \mu \mathrm{L}$ of TE-saturated phenol, mixed and centrifuged. After collecting the aqueous phase, DNA was purified through a silica membrane column and the purified DNA was eluted in $50 \mu \mathrm{L}$ of elution buffer (QIAamp DNA Mini Kit, Qiagen, Hilden, Germany) and was quantified by using NanoDrop (Thermo Fisher Scientific, Waltham, MA, USA).

\section{Bisulfite conversion and real-time PCR}

Two hundred ng of the tooth-derived genomic DNA was denatured by 0.3 $\mathrm{M} \mathrm{NaOH}$ for $15 \mathrm{~min}$ at $37^{\circ} \mathrm{C}$ and then treated with sodium bisulfite for converting any unmethylated cytosine residues into uracil. The converted DNA was eluted in 25-50 $\mu \mathrm{L}$ of elution buffer according to the protocol (MethylEasy Xceed Rapid DNA Bisulphite Modification Kit, \#ME002, Human Genetic Signature, Newtown, Australia).

Subsequently, $2 \mu \mathrm{L}$ of bisulfite-converted DNA template ( $25 \mathrm{ng}$ ) was amplified by real-time PCR in $25 \mu \mathrm{L}$ of a qPCR reaction mixture containing $0.3 \mu \mathrm{M}$ methylation recognition primer targeting the $\mathrm{CpG}$ sequences in the ELOVL2 promoter region (or $0.1 \mu \mathrm{M}$ primer for the human ALU sequence), MSP buffer including $2 \mathrm{mM} \mathrm{Mg}^{2+}$ and $200 \mathrm{mM}$ of each dNTP, TB Green solution and MSP enzyme (EpiScope MSP Kit; TaKaRa Bio, Shiga, Japan). The PCR reaction was run on the Thermal Cycler Dice Real Time System II (TP900; TaKaRa Bio) with an initial denaturation at $95^{\circ} \mathrm{C}$ for $30 \mathrm{~s}$, followed by 45 cycles at $95^{\circ} \mathrm{C}$ for $5 \mathrm{~s}, 55^{\circ} \mathrm{C}$ for $30 \mathrm{~s}$ and $72^{\circ} \mathrm{C}$ for $60 \mathrm{~s}$. Five pairs of methylation-specific primers were designed based on the rules described in Davidović et al. [17]. The best primer set among them was used for analysis. The forward and reverse primers contain 2 CpG (chr6: 11044894, 11044916) and 1 CpG (chr6: 11044974) sites, respectively (Table 1). The melting curve analysis showed a single peak for each tooth sample, suggesting the amplification of only the specific target sequence. As proposed in previous studies $[18,19]$, the ALU repeat was used as a reference in this study. The primer sequences are listed in Table 1.

For semiquantitative MSP, the amount of methylated DNA was determined by real-time PCR. The percent methylated reference (PMR) was calculated based on each sample's threshold $(\mathrm{Cq})$ values for the target and reference gene. The mean $\mathrm{Cq}$ value for each sample was calculated according to the standard curve method. A seven-point standard curve was determined using serial dilutions of commercially known bisulfite-converted methylated and unmethylated standard DNA (EpiScope HCT116
gDNA; TaKaRa Bio): $100 \%, 90 \%, 75 \%, 50 \%, 25 \%, 10 \%$, and $0 \%$. The formula is as follows: [(ELOVL2/ALU) mean value sample / (ELOVL2/ ALU) mean value universal methylated human DNA] $\times 100 \%$ [20].

\section{Statistical analysis}

Each examination was performed in duplicate. The statistical analysis and graphical representations were performed using MS Excel ver. 15.33 (Microsoft, Tokyo, Japan), GraphPad Prism7 (GraphPad Software, San Diego, CA, USA), and Website for Statistical Computation, VassarStats (http://vassarstats.net/). The significant difference among three or more independent groups of sample data (for age groups) was evaluated using one-way factorial ANOVA and then a post-hoc Tukey-Kramer test. Normality of the data was confirmed by calculating Shapiro-Wilk test, and homoscedasticity of data was evaluated by Brown-Forsythe test. Pearson correlation coefficient (r) was used to measure the correlation between PMR and age. The significance of the difference between the two correlation coefficients was analyzed using VassarStats. A $P$-value of less than 0.05 was considered to be statistically significant.

\section{Results}

\section{Genomic DNA extraction from teeth}

Genomic DNA was extracted from 29 teeth from individuals between 20 and 79 years old. The range of the amount of DNA extracted was between 22.3 and $204.4 \mathrm{ng} / \mu \mathrm{L}$ (Fig. 1A, Table 2). No correlation was found between the amount of extracted DNA and the age of donors (Pearson $r=0.353$; Fig. 1B), indicating that collecting efficiency is similar for each tooth. The absorbance OD260/280 ratio available as an indicator of DNA purity was $1.67 \pm 0.141$, demonstrating that DNA quality was suitable for real-time PCR (data not shown).

\section{Correlation between DNA methylation levels and chronological age} To estimate the methylation levels of tooth-derived DNA obtained from individuals of different ages, a $\mathrm{CpG}$ island in the ELOVL2 upstream region was used. A semi-quantitative MSP was done by real-time PCR using two sets of primers specific to DNA molecules methylated at an upstream locus of ELOVL2 gene and to an ALU repeat sequence. The percent methylated reference (PMR) was highly correlated with the actual age (Pearson $r=$ 0.843) (Fig. 2A). The correlation between PMR and chronological age 
Table 2 List of teeth donated in this experiment.

\begin{tabular}{|c|c|c|c|c|}
\hline Age & Sex & Type of tooth & Tooth position & Extracted DNA $(\mathrm{ng} / \mu \mathrm{L})$ \\
\hline 20 & $\mathrm{~F}$ & Molar & 18 & 34.8 \\
\hline 20 & M & Molar & 28 & 60.8 \\
\hline 21 & $\mathrm{~F}$ & Molar & 18 & 141.7 \\
\hline 24 & $\mathrm{~F}$ & Molar & 38 & 62.1 \\
\hline 26 & M & Molar & 48 & 114.7 \\
\hline 28 & $\mathrm{~F}$ & Molar & 48 & 29.1 \\
\hline 28 & U & Molar & 27 & 58.8 \\
\hline 31 & $\mathrm{~F}$ & Molar & 18 & 30.2 \\
\hline 31 & M & Molar & 18 & 28.1 \\
\hline 33 & $\mathrm{~F}$ & Molar & 28 & 140.8 \\
\hline 35 & $\mathrm{~F}$ & Molar & 28 & 51.0 \\
\hline 35 & $\mathrm{~F}$ & Molar & 18 & 172.0 \\
\hline 36 & M & Molar & 18 & 40.7 \\
\hline 37 & $\mathrm{~F}$ & Molar & 38 & 46.3 \\
\hline 44 & M & Molar & 37 & 108.0 \\
\hline 44 & M & Molar & 28 & 66.6 \\
\hline 47 & $\mathrm{~F}$ & Molar & 18 & 22.3 \\
\hline 47 & $\mathrm{~F}$ & Molar & 18 & 25.8 \\
\hline 48 & M & Molar & 48 & 109.9 \\
\hline 51 & M & Molar & 28 & 101.0 \\
\hline 51 & M & Molar & 17 & 184.5 \\
\hline 56 & M & Molar & 38 & 178.7 \\
\hline 59 & M & Molar & 37 & 167.1 \\
\hline 62 & M & Molar & 36 & 41.7 \\
\hline 62 & M & Molar & 27 & 57.2 \\
\hline 64 & $\mathrm{~F}$ & Molar & 17 & 204.4 \\
\hline 70 & M & Premolar & 14 & 91.9 \\
\hline 78 & F & Premolar & 24 & 175.5 \\
\hline 79 & $\mathrm{~F}$ & Molar & 37 & 76.5 \\
\hline
\end{tabular}

F, female; M, male; U, unidentified; Molar, molar teeth; Premolar, premolar teeth


Fig. 2 Correlation between the chronological age and percent methylated reference (PMR). The methylation levels in the CpG island in the ELOVL2 promoter region correlate with chronological age of 29 teeth samples from individuals $(r=0.843 ; A), 14$ samples from women $(r=0.906 ; B)$ and 14 samples from men $(\mathrm{r}=0.784 ; \mathrm{C})$

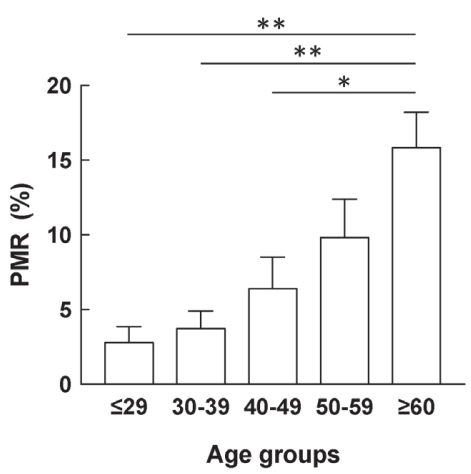

Fig. 3 Bar graph showing chronological age distribution of the methylation levels. Percent methylated reference (PMR) increases with advancing age. One-way analysis of variance, then a post-hoc Tukey-Kramer test. Mean $\pm \mathrm{SEM}, n=29 ; * P<0.05, * * P<0.01$

showed no significant difference between women and men (Two correlation coefficients test, $\mathrm{Z}=1.06, P=0.28$, two-tailed) (Fig. 2B, C).

Change of DNA methylation levels through generations

To investigate the difference of DNA methylation levels among genera- tions, the samples were divided into five groups and the mean of PMR was calculated by each group (Fig. 3). Normality of the data was confirmed by calculating Shapiro-Wilk test $(P=0.0806,0.0707,0.4389,0.9206$ and $0.3019)$, and homoscedasticity of data was evaluated by Brown-Forsythe test $(P=0.321)$. The PMR of each sample was $2.78 \pm 2.6 \%(n=7)$ in the young group (under 29 years old). In the middle-age groups, the PMRs of group I (between 30 and 39 years of age), group II (between 40 and 49 years of age) and group III (between 50 and 59 years of age) were $3.72 \pm$ $2.9 \%(n=7), 6.40 \pm 4.3 \%(n=5)$, and $9.82 \pm 4.5 \%(n=4)$ respectively. On the other hand, the PMR in the elderly group (over 60 years old) was $15.82 \pm 5.4 \%(n=6)$. The results indicate that the DNA methylation levels were associated with advancing age showing a gradual increase in standard error of the mean.

The accuracy of a simple regression model built from 29 training samples

As a next step, ELOVL2 gene was put in a simple regression model to obtain a formula to predict age. The prediction model exhibited some precision with MAD from the chronological age of 8.94 years among 29 training samples (Fig. 4A). The differences between chronological age and predicted age were plotted against chronological age with dots (Fig. 4B). The differences seemed to increase slightly in an age-dependent manner. 

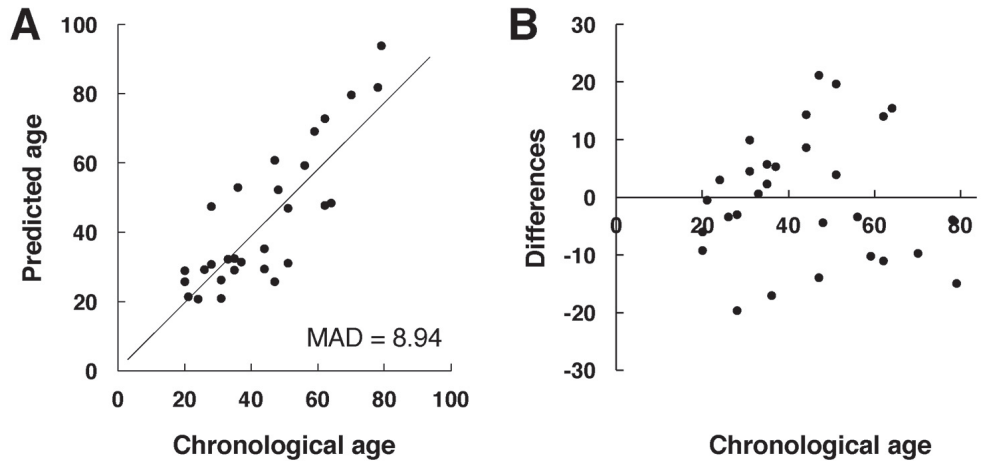

Fig. 4 Validation of the predicted age gained from a linear regression model. (A) Correlation between predicted age and chronological age and corresponding regression line. Twenty-nine training sets of samples are plotted as black circles. (B) Difference between chronological age and predicted age plotted against the chronological age. Mean absolute deviation (MAD) of predicted age against the chronological age is 8.94 years.

\section{Discussion}

The aim of the study was to develop an age prediction model based on $\mathrm{CpG}$ methylation levels of tooth-derived DNA using real-time MSP. Methylation levels of ELOVL2 upstream CpG region were highly correlated with the chronological age. No gender differences were observed in the correlation between $\mathrm{CpG}$ methylation levels and chronological age. Moreover, the age prediction model constructed from $\mathrm{CpG}$ sites of a single gene showed precision with MAD from the chronological age of 8.94 years among 29 training samples.

\section{Validation of DNA extracted from teeth}

Hard tissues including teeth and bones are a good source of DNA for forensic identification of body remains due to their excellent preservation properties. Several groups have reported that teeth are less sensitive to contamination when compared with bone [21,22].

Major sources of DNA from teeth are dentin, dental pulp and cementum [23]. In general, teeth with the largest volume or multi-root teeth provide the best source of DNA [23]. In addition, it is believed that age-dependent degenerative changes in the pulp affect the DNA content of teeth [24,25].

Genomic DNA was extracted from whole teeth by using TBONE EX KIT for DNA methylation analysis. The range of extracted genomic DNA was between 22.3 and $204 \mathrm{ng} / \mu \mathrm{L}$ (Mean $\pm \mathrm{SE}, 90.4 \pm 56.3$ ). The results indicate that the amount of DNA is sufficient to analyze DNA methylation levels using real-time MSP. It was also investigated that whether sufficient DNA content was equally extracted from each sample. DNA content of each tooth was independent of the type of tooth and the age of the donors (Fig. 1B). Moreover, no difference in the purity of extracted DNA was observed in each tooth, demonstrating the validity of experimental results.

\section{An age prediction model based on CpG methylation levels in the promoter region of ELOVL2}

As an age prediction biomarker, DNA methylation has recently been focused on by many researchers including forensic scientists. According to Horvath's report, the average difference in methylation rates for all analyzed loci between young individuals and old individuals is only $3 \%$ per $\mathrm{CpG}$ [11]. In contrast, Garagnani et al. reported that the average difference of a $\mathrm{CpG}$ in the ELOVL2 promoter region was in a range between $7 \%$ and 91\% methylation throughout the lifetime [10]. These reports indicate that ELOVL2 is an attractive candidate for age predictors.

Zbiec-Piekarska et al. examined methylation levels in $7 \mathrm{GpG}$ sites (C1-C7) located in the upstream of ELOVL2 gene in the blood-derived genomes using pyrosequencing [13]. They found that methylation levels of $\mathrm{C} 5$ and $\mathrm{C} 7$ showed a strong correlation with chronological age. Based on the findings, they developed an age estimation model derived from DNA methylation levels in only those two GpG sites $\left(\mathrm{R}^{2}=0.859\right.$, MAD $=5.03$ ). Bekaert et al. also analyzed the methylation status of candidate genes including ELOVL2 and developed a multivariate quadratic regression model in the same way [14]. Interestingly, only C1, C6 and C9, but not C5 and C7, of ELOVL2 were correlated as contributing to their model, with $\mathrm{C} 6$ being by far the most informative $\mathrm{CpG}$ for age estimation. The age prediction by their multivariate quadratic regression model (derived from 4 genes, ADPA, PDE4C, EDARADD, and ELOVL2) showed the high accuracy of a relationship between chronological age and predicted age $(r=0.97, \mathrm{MAD}=3.75$ for blood sample) [14]. They further validated the model with 29 teeth-derived DNA as test samples $\left(\mathrm{R}^{2}=0.74\right.$, MAD $=4.86$ ) [14]. Meanwhile, Giulian et al. attempted to predict chronological age from DNA methylation in ELOVL2, FHL2, and PENK promoter regions of 21 modern teeth samples using EpiTYPER assay [23]. In this case, they selected the $8 \mathrm{CpGs}$ units including $5 \mathrm{CpG}$ sites in ELOVL2 to develop multiple linear regression model.

Based on this previous research, the $\mathrm{CpG}$ sites located in the upstream of the ELOVL2 coding region were used for developing a single regression model. Five pairs of methylation-specific primers were designed and the best primer set among them was used for analysis (Table 1; also see Materials and Methods). The methylation levels of the region were robustly correlated with chronological age of teeth donors $(r=0.843$, Fig. 2A). Moreover, the prediction model showed accuracy with MAD from chronological age of 8.94 among 29 training samples (Fig. 4A).

Bekaert et al. reported that DNA methylation values in the $3 \mathrm{CpGs}$ from ELOVL2 show quadratic relationship with age rather than a straight linear or logarithmic relationship [14]. To verify this issue, determination coefficients were calculated by 3 different methods. Each determination coefficient was Quadratic $\mathrm{R}^{2}=0.51389$; Linear $\mathrm{R}^{2}=0.71042$; Logarithmic $\mathrm{R}^{2}=0.62193$, indicating that the linear regression is better in this model (Fig. 1A). There are some possible reasons for this discrepancy as follows: 1) The sample organs used to build the regression model were different (blood vs. teeth), 2) The relatively small number of samples used to build the regression model (206 vs. 29 samples).

In spite of the relatively low accuracy compared to the other two models, the present model showed a correlation between chronological age and DNA methylation levels in ELOVL2, indicating that real-time MSP based-analysis can be employed for age estimation in the forensic field.

In addition to age, many other factors, such as sex, physiological properties, and diseases, are known to affect DNA methylation levels on some genes $[26,27]$. In the case of the ELOVL2 gene, it has, however, been reported that there is no gender difference in age-associated changes of DNA methylation levels $[14,28]$. The result was consistent with that of previous reports.

\section{Real-time methylation specific PCR is a fast, simple method to quantify methylated-DNA levels}

Pyrosequencing analysis has the advantage of providing information about loci where methylation occurs in the genome. Nevertheless, the method is still not routinely applied for actual criminal investigations due to the high cost and time requirements.

On the other hand, real-time MSP, which is a simple and convenient method, is classified into PCR-based methylation analysis. The method has often been applied for the diagnosis of inherited diseases and various types of cancer $[29,30]$. It is possible to detect the DNA methylation levels of a specific genomic region by the presence or absence of PCR amplification [16]. The method is suitable for analyzing a genomic region with high $\mathrm{CpG}$ 
density and needs only a small amount of genomic DNA.

Hamano et al. have recently reported a novel age prediction model using methylation-sensitive high-resolution melting (MS-HRM) [31,32]. The method is also classified in PCR-based analysis as well as real-time MSP. The method can measure methylation status on bisulfite-treated DNA that is PCR amplified followed by melting analysis [33]. Using this technique, they established an age estimation model and proved the high accuracy of the model $\left(\mathrm{R}^{2}=0.83, \mathrm{MAD}=7.44\right)[32]$. A simple comparison between Hamano's results and the results is difficult, because the combination of genes used to create each age estimation model and the organ to be analyzed is different. MS-HRM is also an excellent tool that is available in forensic scenes as it is an easy and accurate method.

\section{Future plans}

In this study, an age estimation model from tooth-derived DNA using realtime MSP was developed. The simple regression model showed accuracy to age estimation based on methylation level in tooth-derived DNA. So far, a large number of age prediction models based on the DNA methylation in blood have been developed by different laboratories. Many of the models are based on at least 3 different loci of human genome [26,34-37]. It has been reported that the DNA methylation changes are tissue-specific [15]. Therefore, the age estimation model developed using blood DNA should not be directly applied to teeth samples. It is necessary to explore the optimal $\mathrm{CpG}$ sites in some genes for tooth samples to facilitate further refinement of the current model.

\section{Acknowledgments}

The authors would like to thank Dr. Koichi Iwata for his valuable suggestions and comments. The authors also sincerely thank Dr. Nobuyuki Takizawa and a member of Shunpo-kai for encouraging us to achieve our research goals.

\section{Conflict of interest}

The authors have no conflicts of interest to declare.

\section{References}

1. Vidaki A, Daniel B, Court DS (2013) Forensic DNA methylation profiling- potential opportunities and challenges. Forensic Sci Int Genet 7, 499-507.

2. Kader F, Ghai M (2015) DNA methylation and application in forensic sciences. Forensic Sci Int 249, 255-265.

3. Johnson TE (2006) Recent results: biomarkers of aging. Exp Gerontol 41, 1243-1246.

4. Alkass K, Buchholz BA, Ohtani S, Yamamoto T, Druid H, Spalding KL (2010) Age estimation in forensic sciences: application of combined aspartic acid racemization and radiocarbon analysis. Mol Cell Proteomics 9, 1022-1030.

5. Deaton A, Brid A (2011) CpG islands and the regulation of transcription. Genes Dev 25, 1010-1022.

6. Schübeler D (2015) Function and information content of DNA methylation. Nature 517, 321-326.

7. Vidaki A, Kayser M (2018) Recent progress, methods and perspectives in forensic epigenetics. Forensic Sci Int Genet 37, 180-195.

8. Field AE, Robertson NA, Wang T, Havas A, Ideker T, Adams PD (2018) DNA methylation clocks in aging: categories, causes, and consequences. Mol Cell 71, 882-895.

9. Hannum G, Guinney J, Zhao L, Zhang L, Hughes G, Sadda S et al. (2013) Genome-wide methylation profiles reveal quantitative views of human aging rates. Mol Cell 49, 359-367.

10. Garagnani P, Bacalini MG, Pirazzini C, Gori D, Giuliani C, Mari D et al. (2012) Methylation of ELOVL2 gene as a new epigenetic marker of age. Aging Cell 11, 1132-1134.

11. Horvath S (2013) DNA methylation age of human tissues and cell types. Genome Biol 14, R115.

12. Weidner CI, Lin Q, Koch CM, Eisele L, Beier F, Ziegler P et al. (2014) Aging of blood can be tracked by DNA methylation changes at just three $\mathrm{CpG}$ sites. Genome Biol 15, R24.

13. Zbieć-Piekarska R, Spólnicka M, Kupiec T, Makowska Ż, Spas A, Parys-Proszek A et al (2015) Examination of DNA methylation status of the ELOVL2 marker may be useful for human age prediction in forensic science, Forensic Sci Int Genet 14, 161-167.

14. Bekaert B, Kamalandua A, Zapico SC, Van de Voorde W, Decorte R (2015) Improved age determination of blood and teeth samples using a selected set of DNA methylation markers. Epigenetics 10, 922-930.

15. Slieker RC, Relton CL, Gaunt TR, Slagboom PE, Heijmans BT (2018) Age-related DNA methylation changes are tissue-specific with ELOVL2 promoter methylation as exception. Epigenetics Chromatin 11, 25.

16. Herman JG, Graff JR, Myöhänen S, Nelkin BD, Baylin SB (1996) Methylation-specific PCR: a novel PCR assay for methylation status of $\mathrm{CpG}$ islands. Proc Natl Acad Sci USA 93, 9821-9826.

17. Davidović RS, Božović AM, Mandušić VLj, Krajnović MM (2014) Methylation- specific PCR: four steps in primer design. Cent Eur J Biol 9, 1127-1139.

18. Weisenberger DJ, Campan M, Long TI, Kim M, Woods C, Fiala E et al. (2005) Analysis of repetitive element DNA methylation by MethyLight. Nucleic Acids Res 33, 6823-6836.

19. Niwa T, Tsukamoto T, Toyoda T, Mori A, Tanaka H, Maekita T et al. (2010) Inflammatory processes triggered by Helicobacter pylori infection cause aberrant DNA methylation in gastric epithelial cells. Cancer Res 70, 1430-1440.

20. White-Al Habeeb NM, Ho LT, Olkhov-Mitsel E, Kron K, Pethe V, Lehman M et al. (2014) Integrated analysis of epigenomic and genomic changes by DNA methylation dependent mechanisms provides potential novel biomarkers for prostate cancer. Oncotarget 5, 78587869.

21. Kitayama T, Ogawa Y, Fujii K, Nakahara H, Mizuno N, Sekiguchi K et al. (2010) Evaluation of a new experimental kit for the extraction of DNA from bones and teeth using a non-powder method. Leg Med (Tokyo) 12, 84-89.

22. Higgins D, Austin JJ (2013) Teeth as a source of DNA for forensic identification of human remains: a review. Sci Justice 53, 433-441.

23. Giuliani C, Cilli E, Bacalini MG, Pirazzini C, Sazzini M, Gruppioni G et al. (2016) Inferring chronological age from DNA methylation patterns of human teeth. Am J Phys Anthropol 159, 585-595.

24. Adler CJ, Haak W, Donlon D, Cooper A (2011) Survival and recovery of DNA from ancient teeth and bones. J Archaeol Sci 38, 956-964.

25. Pilli E, Modi A, Serpico C, Achilli A, Lancioni H, Lippi B et al. (2013) Monitoring DNA contamination in handled vs. directly excavated ancient human skeletal remains. PLoS One 8 , e52524.

26. Boks MP, Derks EM, Weisenberger DJ, Strengman E, Janson E, Sommer IE et al. (2009) The relationship of DNA methylation with age, gender and genotype in twins and healthy controls. PLoS One 4, e6767.

27. Oka D, Yamashita S, Tomioka T, Nakanishi Y, Kato H, Kaminishi M et al. (2009) The presence of aberrant DNA methylation in noncancerous esophageal mucosae in association with smoking history: a target for risk diagnosis and prevention of esophageal cancers. Cancer 115, 3412-3426.

28. Daunay A, Baudrin LG, Deleuze JF, How-Kit A (2019) Evaluation of six blood-based age prediction models using DNA methylation analysis by pyrosequencing. Sci Rep 9,8862 .

29. Ushijima $T$ (2005) Detection and interpretation of altered methylation patterns in cancer cells. Nat Rev Cancer 5, 223-231.

30. Yamashita S, Takahashi S, McDonell N, Watanabe N, Niwa T, Hosoya K et al. (2008) Methylation silencing of transforming growth factor-beta receptor type II in rat prostate cancers. Cancer Res 67, 2112-2121.

31. Hamano Y, Manabe S, Morimoto C, Fujimoto S, Ozeki M, Tamaki K (2016) Forensic age prediction for dead or living samples by use of methylation-sensitive high resolution melting. Leg Med (Tokyo) 21, 5-10.

32. Hamano Y, Manabe S, Morimoto C, Fujimoto S, Tamaki K (2017) Forensic age prediction for saliva samples using methylation-sensitive high resolution melting: exploratory application for cigarette butts. Sci Rep 7, 10444.

33. Wojdacz TK, Dobrovic A, Hansen LL (2008) Methylation-sensitive high-resolution melting. Nat Protocol 3, 1903-1908.

34. Lee HY, Jung SE, Oh YN, Choi A, Yang WI, Shin KJ (2015) Epigenetic age signatures in the forensically relevant body fluid of semen: a preliminary study. Forensic Sci Int Genet 19, 28-34.

35. Park JL, Kim JH, Seo E, Bae DH, Kim SY, Lee HC et al. (2016) Identification and evaluation of age-correlated DNA methylation markers for forensic use. Forensic Sci Int Genet 23, 64-70.

36. Lee HY, Lee SD, Shin KJ (2016) Forensic DNA methylation profiling from evidence material for investigative leads. BMB rep 49, 359-369.

37. Jung SE Lim SM, Hong SR, Lee EH, Shin KJ, Lee HY (2019) DNA methylation of the ELOVL2, FHL2, KLF14, C1orf132/MIR29B2C, and TRIM59 genes for age prediction from blood, saliva, and buccal swab samples. Forensic Sci Int Genet 38, 1-8. 